well ; inflammatory redness had entirely dieappeared; the edges of the wound, which were filled with clot, were white; the discharge consisted merely of serous fluid, which oozed from the clot. $\mathrm{He}$ slept well without a draught; felt so much better and so much more cheerful that he said "he felt as if a new life had been given him." - 30 : Ulcer on third toe completely healed.June 2nd : Small toe almost healed, and clot in next nearly organised. $-4 \cdot h$ : Little toe well except superficial sore ; next toe nearly healed. Got up. $-6 \mathrm{th}$ : There being only a superficial sore, boracic dressing substituted for the carbolic. -10th: Wound quite healed.-23rd: Discharged well, except that for a few days he had complained of a slight pain in the other foot.

The patient was readmitted on April 25th, 1883, eleven months after the operation. The right foot remained quite sound; but of the left foot the middle toe was quite black and dead; there were black patches on the adjoining on $*$ s, and all the toes were more or less purplish-black, with inflammatisn and oedema extending to the ankle-joint. $\mathrm{He}$ was suffering a great deal of burning pain, and appeared very despondent. He was ordered a nourishing diet, with three ounces of brandy ditly. To be kept in bed, and the foot wrapped in cotton-wool.-May 12th : The black patch on the middle toe considerably larger, and the foot altogether worse. He seemed greatly distressed and hopeless, and would not hear of any operation. Quinine and iron mixture prescribed; but as he continutd to refuse any operation he went out of the hospital on May $30 \mathrm{th}$, rather more than a month from his admission, but returned in about three weeks and was again admitted.-June ISth: His foot having continued to get worse, and he having made up his miod to submit to any necessary operation, he was ordered the same diat, with six ounces of brandy daily instead of four. -19 th : Pulse 84 ; morning temperature $976^{\circ}$, evening $988^{\circ}$. Foot extremely painful, swollen, and codematous, with increased blackness of toes, Anxiety and distress increased.-20th: The distal half of the foot was amputated, the metataisal, cuneiform, and cuboid bones were removed. The flaps were superior and inferior, being both of equal length and composed of extremely sederuatous and inflamed tissues; in addition to the dressings used last

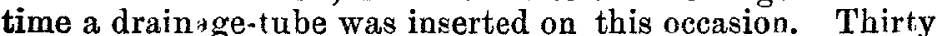
minims of liquor morphiæ were prescribed. Palse 90; morning temperature $98.4^{\circ}$, evening $99.8^{\circ}$.-2lst: Slept well, and felt so much better both generally and in the foot than before the operation that he again used the expression that he "felt as if a new life had been given him." Wound dressed, which looked very well excert that there were one or two rather dark specks at the edge of the incision, some of the stitches which appeared rather tense were removed. Morning temperature $99.8^{\circ}$, in the evening it reached $100^{\circ}$, being the highest point attained; from this period it steadily declined to rather below normal, which seemed to be his usual temperature. Pulse 84 , which the day before reached 90 , the highest recorded during his stay in the hospital-22ud: Wound dressed, which seemed to be healed across except the skin, and this was dark at the stitches, removed all remaining except one at each end.24th: Wound dressed, edges continued dark, but less so than on the 22nd; remaining two stitches removed. Taking food well.-26th: Wound dressed, very little discharge; drainage-tube shortened. Some pain in abdomen. Pulse 84 ; morning temperature $98^{\circ}$, evening $986^{\circ} .-29$ th : Wound dressed. There was a small superficial slough along part of the edge of the wound.-July 4th: Wound skinned over, looking healthy, but outer side of heel dark and painful. Temperatue $98^{\circ} 4^{\circ}$. - 11th : Left off carbolic dressing and substituted boracic. Wound looking very well. On the outer side of heel there is a sloughy sore, the central slough being surrounded by healing edges. -15 th : Wound looking healthy; sore under heel healing. From this time he went on improving slowly, until, the wound having entirely healed, he was discharged on August 12th.-On Nov. 14th, nearly five months after the second operation, he was shown at a meeting of the Bristol Medico-Chirurgical Society. The right foot was perfectly sound ; the left quite healed, but, as far as the aukle-joint, slightly swollen, and rather tender when he step; upon it.

I consider this case important, because the treatment of senile gangrene, as laid down by authorities, is extremely unsatisfaciory. For almost all writers, while ackrowledging that if left alone it will steadily go on from bad to worse, generally ending fatally in about a month or eight weeks, but sometimes not for twelve months, say that amputation will probably be useless, especially before the line of de. marcation is well establisbed. Some few surgeons do advo. cate amputation, but only at a great distance from the gangrene, a successful case of which we had at the hnspital a short time ago under the care of Mr. Dobson. ${ }^{1} \mathrm{Mr}$. Watson Cheyne, in his book, which I have read since ny second operation, advocates theoretically early amputation, but I believe this is the first instance in which it has been suc. cessfully performed. The perfect success that resulted from the first operation I think remarkable, especially as the incisions were made through inflamed and cedematous tissues; the bones were subjected to the violence of the bone forceps; and, above all, that the ulcer on the third toe produced by the irritation of contact with the gangrenous fourth toe healed so rapidly. To look at the right foot now one would hardly suppose that it was so near to destruction by senile gangrene some eighteen months go. The other, that on the left foot, I take to have been still more remarkable, although the mutilation of the foot was greater and the stump not quite so healthy-looking as the other foot, because my incisions were made through such extremely unfavourable tissues, for they were dis. coloured, swollen, and very codematous, being full of watery looking fluid, which exuded freely during the operation.

Now, are we to look upon these results as being entirely due to goud fortune, or can we assign any probable reason, and is there anything to be learned from them? I must confess that I think they go to confirm the opinion that the con. tinued spread of senile gangrene is caused by the local irritation of the contact of putrefying dead matter with the living but slightly resisting tissues-i.e., tissues whose vital powers of destroying low forms of life are very small, and that if one can remove all possibility of putrefaction, even if one has to resort to the violence of an amputation, and that through very unpromising tissues, one may save the patient. In the second case this was shown even more than the first, for bere the amputation was made through parts of such extremely low vitality that slough;, small rertainly, formed at several of the stitch points, as well as along the extreme edge of the wound, and again the integuments of the heel sloughed from the weight of the part of the foot, although great care by padding with cotton.wool was taken to prevent it. How is it that this sloughing did not spread? What was the difference between the sloughs and the gangrenous toes? The gangrene of the toes would have gone on spreading until death ensued, while the sloughs remained quiet, did not spread, but were either absorbed or came away in the dressings, leaving a healing surface beneath them. The only difference I can recognise with regard to the tendency to spread, is that the toes were in a state of putrescence at the points of contact with the living tissues, while the other sloughs were entirely free from any putrefaction; and this being the case, I should feel inclined to amputate early tbrough moderately healthy tissues, and sbould expect to prolong the life of my patient, and this view is supported by the better result in the case of the right foot. In case of recurrence of the gangrene I should again amputate. Bristol.

\section{A CHART FOR RECORDING URETHRAL MEASUREMENTS.}

\section{By GEORGE HERSCHELL, M.D. LOND.}

THE annexed woodeut represents a portion of a chart which I have had engraved for my own use, and which I have found of great assistance in keeping records of my stricture cases. It consists essentially of a series of vertical and horizontal lines crossing one another at right angles. Taking the extreme left hand vertical line to represent the meatus urinarius, the other vertical lines will denote distance from the meatus and are numbered in centimetres. The horizontal lines denote the circumference of the urethra in millimetres. There is an obvious advantage in having the circumference and not the diameter represented, from the fact that the circumference in milli-

1 Since this was written, $\mathrm{Mr}$. Jonathan $\mathrm{H}$ utchinson has read a paper before the Royal Medical and Chirurgical Society, adrocating the high amputation. 
metres of all instruments according to the metric, or the French scale is practically identical with the number marked upon the handle of the instrument-that is to say, that for all practical purposes a urethra which will just admit a No. 30 French scale, may be taken to have a circumference of thirty millimetres. For this reason, and also from the fact that while the successive instruments of the English scale are separated from each other by intervals of varied length, the sizes of the French scale proceed regularly by a constant increment of one millimetre in circumference, the former has been virtually abandoned in favour of the latter by all surgeons of the modern school who have much to do with stricture cases. Such being the case, it follows that any plane perpendicular to the axis of the urethra may be represented by the point of intersection of a vertical and a horizontal line upon the chart, both as regards the calibre of the urethra in that plane and its distance from the meatus respectively. By measuring a sufficient number of such consecutive planes in the urethra with the exploring bulb, or if the meatus is contracted, with the urethrometer, marking these points upon the chart, and joining them, a diagrammatic representation of the urethra will be obtained, which obviously conveys at a

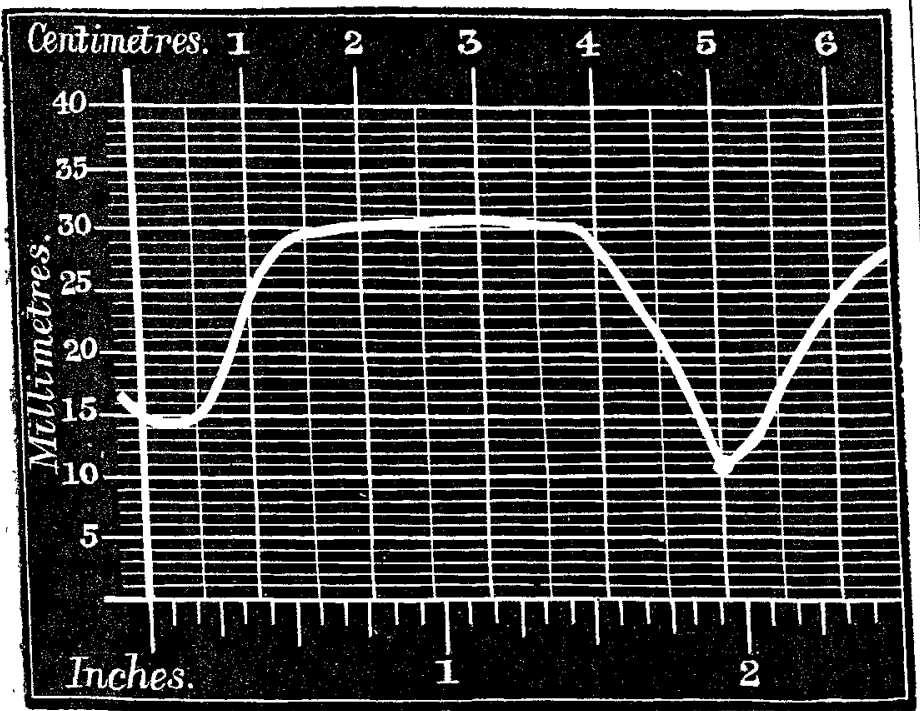

glance a more distinct idea of that canal in its totality than any written description could possibly do. The normal calibre of the urethra should be ascertained either by the ratio that $U$ tis has demonstrated to exist between the circumference of the flaccid penis and that of the urethra, or preferably by means of the urethrometer, and filled in upon the chart between the points of contraction. As an example the woodcut represents a urethra of a normal calibre of thirty millimetres with a meatus contracted to just admit a No. 15 bulb, this contraction extending to a depth of half a centimetre. Another stricture defined by a No. 10 bulb is present at five centimetres from the orifice, the urethra between these points expauding to its ascertained normal calibre of thirty millimetres.

There are two points in urethral pathology which are yet unsettled - namely, the average normal calibre of a healthy urethra, and the locality of the greatest frequency of stricture. I hope that these charts, by affurding a ready means for the accurate recording and comparison of uretbral measurements, may remove some of the obstacles to the accumulation of the data necessary to solve these important problems.

Moorgate-street, E.C.

\section{COMPLETE ABSENCE OF JEJUNUM, ILEUM, AND THE GREATER PART OF THE COLON.}

BY WILLTAM THOMAS, F.R.C.S., PROFESSOR OF ANATOMY, QUEEN'S COLLEGE; SURGEON TO THE F ANATOMY, QUEEN'S COLLEGE; SURG
CHILDREN'S HOSPITAL, BIRMINGHAM.

F. D-, aged two days, was sent to me by Dr. Richards on October 20th. The child had been born prematurely (seven months), and on examination no trace of anus was visible in the normal situation. The labia were comparatively large; on separation no urethral orifice was visible, but a probe passed in the direction of the urethra for about two ches could readily be felt through the abdominal wall bove the pubes, and was followed by the escape of a few pear fluid. A second could be passed along the perior wall of the vagina in the direction of the rectum for ore than three inches; this excited the expulsion of about teaspoonful of pale, yellowish, gelatinous mucus. The abdomen was not distended, and seemed smaller than normal, especially in the lower part. The child had taken the breast, ut had been sick continually, not retaining food many minutes. It was decided that come congenital malformation of the bowel existed and that no operative proeeding could be undertaken with a reasonable prospect of uccess.

Oct. 21st. - Worse ; cannot take the breast, but swallows a ittle milk and water. Has thrown up a quantity of stuff said to resemble "a baby's pale motion." The skin is much yellower than yesterday, and the child altogether weaker.22nd: The child gradually got weaker and died this morning. I was not immediately informed of the child's death, in consequence of which there was delay in obtaining permission to make a post-mortem. The examination had to be made within an hour of the time appointed for the funeral, and was not so complete as desirable, only the abdominal viscera being examined.

The following notes were taken by Dr. Powell, resident medical officer at the Children's Hospital, who kindly assisted me:-Rigor mortis almost absent; skin generally of a brownish-yellow, with a considerable amount of post-mortem lividity. On opening the abdomen, and prolonging the incision downwards, it was found there was no union of the pubic bones, an interval existing between them large enough to admit a finger. There was no great distension of the abdomen; the great omentum was adherent in various places to the parts beneath. The stomach was of normal size, moderately distended, and connected with the duodenum by a constricted pylorus half an inch in length and rather less in diameter. On raising the great omentum the duodenum was found to occupy the greater part of the abdominal cavity. It was about an inch and a half in diameter in the distended state, and curved round the pancreas, to terminate on the left side of the spine by a blind extremity. There was no trace of any other part of the small intestine, nor of the cæcum, ascending or transverse colon. The intestine was recommenced by a blind portion of descending colon lying on the lower end of the left kidney, and continued by a sigmoid flexure and rectum, to terminate in the vagina The liver was of normal size; the gall-bladder contained bile, but was not distended. There was nothing unusual about the kidneys, spleen, or pancreas.

Birmingham.

\section{CASES IN MIDWIFERY PRACTICE.}

\section{BY J. R. FORREST, M.R.C.S., \&c.}

PREGNANCY IN A PATIENT WITH FIBROID TUMOUR OF THE UTERUS.

MRs. W—, aged twenty-four, a primipara, was attended by me in her confinement. She was a healthy-looking woman, who said she had never suffered from any serious illness. She had a sister who died nine days after bearing her first child, death being attributed to suppression of the lochia. Her mother, still living, always had difficult labours. My patient was taken in labour about 2 P.M. I was summoned at $10 \mathrm{P} . \mathrm{M}$., and found the pains returning at intervals of about ten minutes. Abdominal palpation revealed the outline of the spine of the child with the concavity to the right, but the breech was not to be discerned. Towards the fundus of the uterus, and on the right side, a hard rounded swelling, dull on percussion, of the size of the foetal head, could be made out, but on examination per vaginam the head could be felt presenting in the first position. The os uteri was dilated to the size of half a crown on my arrival, the anterior portion of the cervix capping the foetal head, so that the os was carried far towards the sacrum. The cervix proving extremely rigid, I introduced a Barnes' bag (No. 1), and then No. 2. The liquor amnii was greatly pent-up by the foetal head, so, puncturing the membranes, $I$ introduced one blade of the torceps, and using this as a vecti , I succeeded in pushing aside the valve formed by the cervix. From the result of my previous examination by abdoninal palpation I felt sure that all was not right, 